\title{
ACCIDENTS CAUSED BY THE DIFFERENCE IN GIR PRESSURE INSIDE THE DIVING APPARATUS AND THE WATER SURROUNDING THE DIVER
}

\author{
Augustyn Dolatkowski \\ Department of Maritime Medicine of the Military Medical Academy in Gdynia, Poland
}

\section{ABSTRACT}

This paper describes 4 unfortunate accidents caused by the difference in pressure inside and outside the diver's suit. The issues relate to diver crushing, caisson disease, too fast an ascent to the surface and hypoxia as a result of exhaustion of oxygen in the diving apparatus are explained. The mechanism of the diving injuries was analysed and methods of prevention of such incidents were suggested.

Keywords: hypoxia, diver crushing, diver ejection, pulmonary barotrauma.

\section{ARTICLE INFO}

PolHypRes 2018 Vol. 64 Issue 3 pp. 45 - 54

ISSN: 1734-7009 elSSN: 2084-0535

DOI: $10.2478 / \mathrm{phr}-2018-0018$

Pages: 9, figures: 4 , tables: 0

page www of the periodical: www.phr.net.pl

Publisher

Polish Hyperbaric Medicine and Technology Society
Casuistic article (case description)

Originally published in "Lekarz Wojskowy" 1961 Acceptance for print in PHR: 08.08.2018 r. 


\section{INTRODUCTION}

Insufficient knowledge of diving diseases by most doctors narrows their angle of view on disorders during gas exchange occurring in the diver's system exclusively to caisson disease (decompression syndrome).

Meanwhile, the disproportion between the pressure of the air inside the suit and the pressure of the water column outside the suit is a sufficient reason to induce a whole series of damage to the diver's body, regardless of the decompression sickness.

I am going to cite four observed cases and discuss the disturbances in the exchange of air in the diving suit which, in three of these cases, led to very serious conditions for the divers.

The first accident took place during diving exercises at a depth of $40 \mathrm{~m}$. The diver, who was assessed by a doctor as capable of diving, initiated diving while feeling well. While descending to the prescribed depth of $30 \mathrm{~m}$, the diver remained in constant contact with the crew on board the base ship and was feeling good. After passing the depth of 30 meters, the contact was suddenly broken and the diver did not respond to signals. He was extracted at a rather rapid pace to the surface. The diver was found to be unconscious. The skin of the face and eyelids was heavily swollen and bluish and so were the mucous membranes, with accompanying redness of conjunctivae.

After removing his suit, it was found that cyanosis and swelling of the skin reached through the neck to the upper chest, cutting off with a straight line both in the front and the back on the chest. The arched line corresponded to a metal cape on which the diving helmet was mounted and screwed. The diver's breath was superficial. Despite the use of stimulants of the respiratory system and circulatory system with simultaneous compression and subsequent therapeutic decompression in the pressure chamber, the patient did not regain consciousness and died onboard the ship. The characteristic appearance - cyanosis and swelling of the upper part of the chest, neck, face and head with subcutaneous haemorrhages is evidence of the diver's crushing which occurred during the diver's descent.

A very important condition for the proper functioning of the human system is the balancing of the pressure inside the suit with the external pressure, which is obtained by a regulated supply of compressed air in response to the diver's immersion. Proper cooperation of the diver in regulating the supply of air in the suit is extremely valuable. When the speed of descent does not correspond to the amount of air supplied, i.e. the pressure inside the suit does not keep up with an increase in external pressure, the diver is crushed. This situation occurs, for example, when the diver falls from the wreck deck to the seabed, or during exercises when the diver does not hold on to the tether line.

In the case described above, the diver fell from a depth of $30 \mathrm{~m}$ to $40 \mathrm{~m}$, which means that the external pressure rose from four atmospheres to five. Since the diving suit is susceptible to compression, with the exception of the helmet and metal cape, an evenly distributed pressure on the torso and limbs causes compression towards the head and the upper torso. This pressure has a particular effect on soft tissues and bodily fluids. Hence the swelling of the skin and subcutaneous tissue of the head, neck and upper chest, as well as the organs located within this part of the body. This is equivalent to the action of a suction bubble and the French authors refer to it as "coup de ventouse" [7]. With a significant difference in pressure it may lead to tissue rupture or even a fracture of the clavicle, ribs and spine.

In terms of severity of injury, the pressure surge plays an important role. In this case, the pressure surge was $25 \%$ of the primary pressure as it suddenly rose from four to five atmospheres, which was enough to cause such a serious injury. The higher the pressure leap, the more intense the damage and, hence, it is understandable that a fall from a surface at a depth of $5 \mathrm{~m}$ is much more dangerous than a fall from $20 \mathrm{~m}$ to $25 \mathrm{~m}$. This applies to a classic suit.

The autopsy description corresponded to the described mechanism of crushing: the face, scalp, neck and neck skin and chest near the collars, upper part of the sternum, and at the back above the shoulder blades, were swollen and bruised. Bruised conjunctivae with small, punctiform petechiae. In the temporal muscles numerous extensive haemorrhages, liquid dark red blood, venous vessels overfilled with blood, protruding above the regular level. Numerous dark red petechiae scattered all over the surface of the white matter of the brain. The bridge, cerebellum and extended spinal cord also show punctiform haemorrhages, the neck muscles exhibit numerous dark blue-red haemorrhages. The lungs fill the chest - they do not collapse, are large, not too heavy, give out a cracking noise when compressed; the edges are rounded, the surface is smooth red, and when compressed they become richly covered with red, foamy liquid.

Right ventricle large, water test reveals gas in the right ventricle. Under the epicardium and under the pleura numerous petechiae. Liquid blood.

Severe damage to the brain, cerebellum and prolonged spinal cord has been identified as the primary lethal injury. As shown by the autopsy findings, the state of the lungs indicting pulmonary oedema, requires further discussion. It should be assumed that it originated due to a reflex reaction and is of vascular and motor origin. This is a common consequence of skull injuries, as well as injuries to other parts of the body, it also occurs following major surgical procedures [8].

In addition, as a symptom of pressure disease as a result of a too rapid extraction of the diver, without performing the required decompression stops due to the diver's lack of response to signals, an air embolism of right chamber of the heart appeared, which was formed during the extraction of the diver to the surface and during his transfer to the recompression chamber on the ship. It is conceivable that it grew to a definite size and after death, as decompression is subject to physical laws and the difference in partial pressures of air gases [1]. The principle that applies to decompression is the time interval of no more than two and a half minutes from the appearance of the diver on the surface until the commencement of compression in the chamber [3]. In this case, despite the quickly provided help, the diver could not be saved.

The second accident involved a trainee diver practising in an outdoor pool at a depth of $4 \mathrm{~m}$ (fig. 1). 


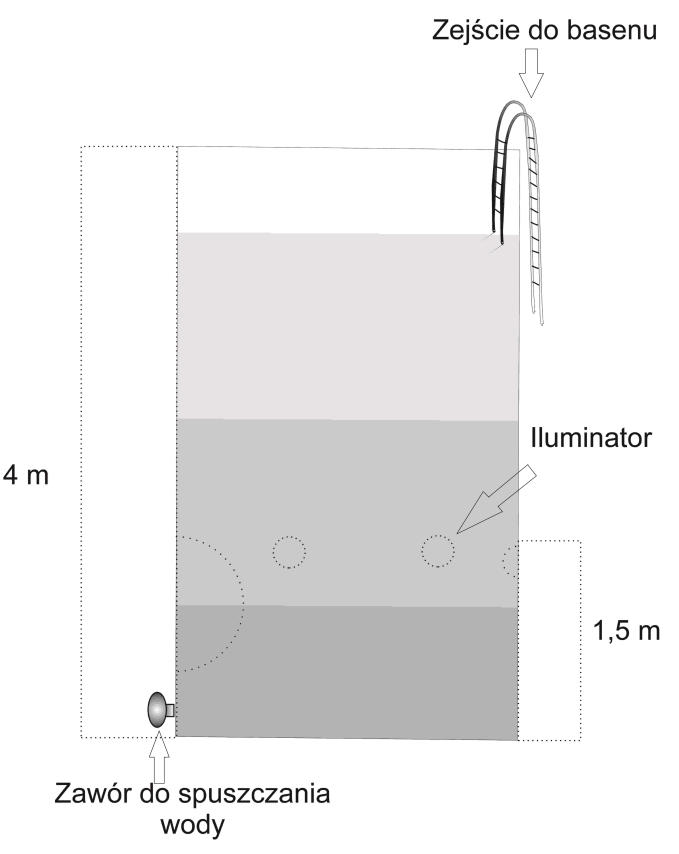

Fig. 1 Diagram of the pool construction

The diver trained wearing an individual ISAM type rescue apparatus. One of the first exercises consisted in putting on the rescue apparatus and staying in it for a few minutes while under water.

There are several types of individual rescue apparatuses. For example, ISAM, Davis, Draeger, Mommsen-lung [6]. They are used when leaving a sunken submarine, as well as for short-term stays underwater for reconnaissance purposes. This type of equipment has led to the development of aqualungs, i.e. scuba equipment.

In this type of breathing apparatuses, breathing is realised through the mouth, as the respiratory tube is ended with a mouthpiece that the diver inserts between the teeth. Exhalation, depending on the type of apparatus, can be performed in such a way that the stream of exhaled air goes into the apparatus itself, where the air is purified from carbon dioxide by the absorber - in which case we talk about a closed-circuit apparatus, or exhalation takes place through a valve outside the apparatus, as is the case with an open-circuit apparatus. In the latter case, bubbles of exhaled air escape to the surface, preventing the diver from moving discreetly under water. The first type of device is an individual ISAM rescue device (Fig. 2), which has a protective mask that is stretched on the face.

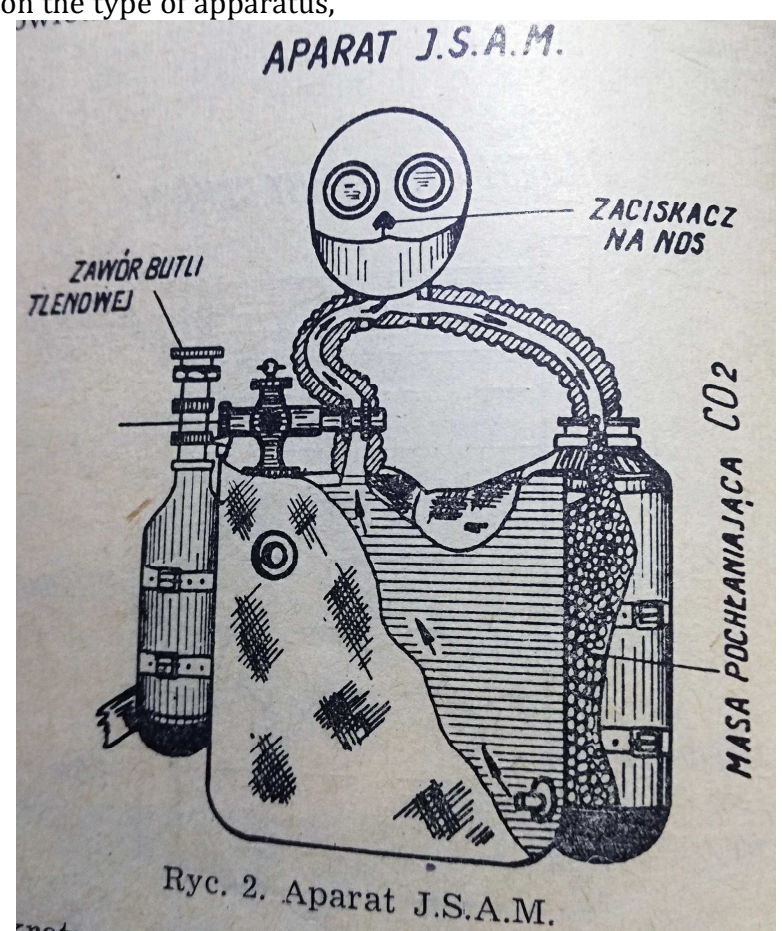

Fig. 2 Apparatus J.S.A.M (drawing scan from the original work). 
The mask itself, apart from its protective function, has no influence on the breathing process. These devices are equipped with oxygen cylinders. The improvement in ISAMs is a special button which pops out with a characteristic knock when the oxygen supply in the cylinder is depleted. This is the signal for the diver to begin the ascent to the surface.

In the second case, as a result of an insufficiently tight mask, some water got inside the mask, and the diver choked, became panicked, stopped breathing and emerged at the surface. When he was pulled out of the pool he had blacked out, began to vomit, was haemorrhaging from his nose and lost consciousness. After the diver was extracted from the pool, his mask was removed and artificial respiration was applied. After the diver regained consciousness, he was taken to hospital. In medical interviews, the diver reported breathing difficulties while wearing the apparatus, a burning sensation in the conjunctiva, severe weakness and strong headaches.

The current status according to the disease history: reddened conjunctivae, lips and eyelids with slight bluish coloration, patient complaining about headaches - especially in the nasal area, shortness of breath, accelerated breathing at the rate of 22 breaths per minute, lung respiratory sounds over the lower parts of the lungs weakened, dull resonance on percussion over these parts of the lungs, heart rate 100 per minute, RR 120/60 mm Hg., heart sounds hollow. Subfebrile states were diagnosed for a week, after which the body temperature returned to normal. Chest X-ray showed: clouding throughout both lung fields - reduced lung aeration. From other results it is worth emphasizing leukocytosis 13.900 , which gradually returned to normal after 10 days. OB 64 after 1 hour, 24 after 2 hours. Cerebrospinal fluid unchanged. In addition, a neurological examination on the fifth day after the accident revealed residual symptoms of cerebral oedema (severe headaches, paresis of the oral branch of the left facial nerve). Aspiration pneumonia and swelling of the brain were diagnosed. After 37 days of hospital treatment, the patient was referred to a psychiatric institution because of the symptoms of reactive psychosis.

In this case, as a result of choking, the glottis and apnoea were reflexively blocked. Such a state maintained when bringing the diver to the surface caused the pressure inside the airways to remain at the same level as at a depth of $4 \mathrm{~m}$. When the diver was extracted to the surface, the difference between the pressure inside the airways and the external pressure was 0.4 atmospheres. In this case, the mask of the individual rescue apparatus made it even more difficult to equalize the pressure. All in all, this led to the development of pseudo-caisson disease (pulmonary barotrauma). The difference of 0.2 atmospheres between the pressure inside and outside the airways is enough to cause lung tissue damage. Pulmonary congestion and haemorrhages occur in the respiratory tract and in the lungs. In the discussed case, the radiological picture of the lungs confirmed this. The symptoms and treatment are similar to those in caisson disease, however, if with the latter gas bubbles are found in the bloodstream due to the release of nitrogen from the blood, then with pseudo caisson disease air bubbles get into the bloodstream from the bronchial light due to damage to blood vessels. To emphasize the difference in the mechanism of the disease, the authors called it a pseudo-caisson disease [5]. One of the consequences of pseudo-caisson disease is cerebral oedema, which is of course a very serious complication.

This disease is more common in seafarers leaving a sunken submarine and ascending to the surface in individual rescue equipment than in divers. The unjustified fear that the supply of air or oxygen may not be sufficient for the time of exiting the depths leads to a breathing arrest, which causes serious damage due to pseudo-caisson disease when the pressure drops while performing the ascent.

The third accident involved a diver working at a depth of $30 \mathrm{~m}$ in a classic suit. After working for half an hour, i.e. after a normal period of stay on the bottom, the diver was instructed to return to the surface. At this point it is very important that the diver is skillfully cleared from the bottom as in order to achieve positive buoyancy, the diver keeps a little more air in the suit. However, this amount should be adjusted in such a way that the diver can stop at the prescribed stations, in this case at the depth of 9 and $6 \mathrm{~m}$, and then at the depth of $3 \mathrm{~m}$. As a result of faulty regulation of the air supply, the diver ascended to the surface, with the suit being balloonbloated.

In such a situation, the diver is usually ejected in an upside-down position unable to bend either arms or legs, and cannot reach with his hand or head the pressure-reducing valve stem in the suit, and only quick help from outside can release excess air, which protects the suit from bursting and the diver from drowning. Too rapid an ascent from the depths without observing the necessary decompression stops can result in an occurrence of caisson disease (decompression sickness).

After releasing the air, the diver descended to half the dive depth, i.e. down to $15 \mathrm{~m}$, from which he returned to the surface in accordance with the decompression time tables without any adverse consequences.

The fourth case concerned a 26-year-old diving instructor, who enjoyed a very good reputation as a professional, performing his duties for 5 years. The accident, which ended with the instructor's death, took place in a training diving pool with a depth of $7 \mathrm{~m}$ (Fig. 3). The instructor's task was to prepare the pool for training the crew within leaving a sunken submarine. In order to create the same conditions as in the submarine in an emergency situation, the manhole between the upper and lower compartments of the pool is closed and the lower compartment is filled with water heated to a temperature of 24 degrees Celsius.

With the manhole closed, as the water rises, the air is pressed under the dome of the partition and is trapped in the space between the dome and the flange of the manhole, thus creating the so-called air cushion. Next, water is poured into the upper compartment. To prepare the pool for the training, the instructor descends into the pool, opens the manhole cover and checks the state of the air cushion. The task of the instructor is to go down through the manhole to the lower compartment of the pool and assume a position where the head is located within the air cushion. 


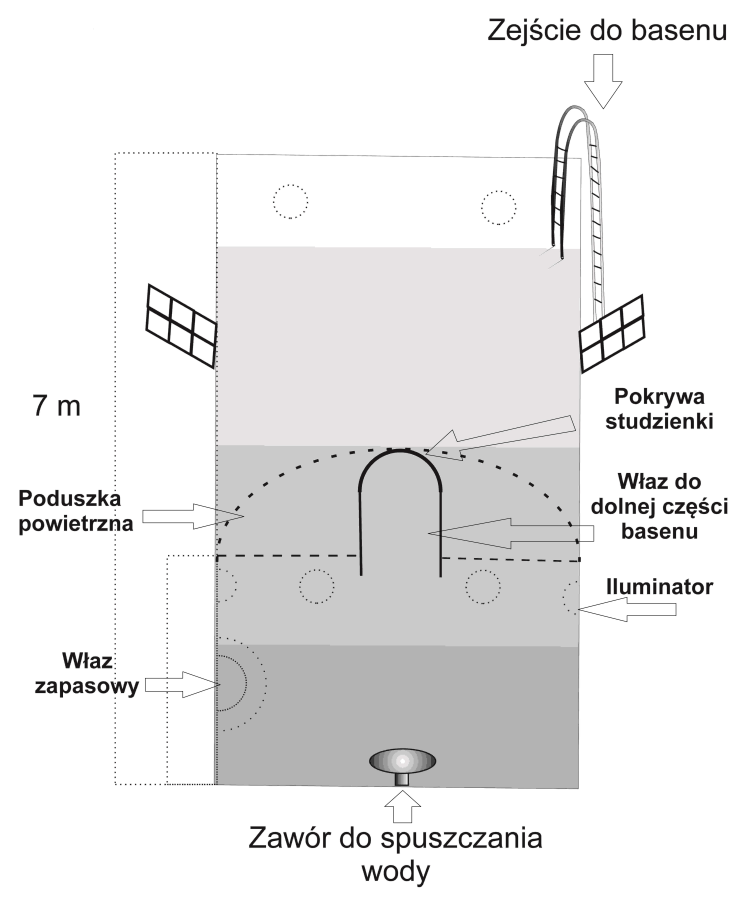

Fig. 3 A two-compartment training pool.

As soon as the trainee wearing an individual rescue apparatus positions himself within the air cushion he takes off the apparatus and breathes with the air trapped under the dome, then again puts on the rescue apparatus and moving under the edge of the manhole exits through the manhole into the upper pool compartment and ascends to the surface. This method is identical to escaping from a sunken submarine.

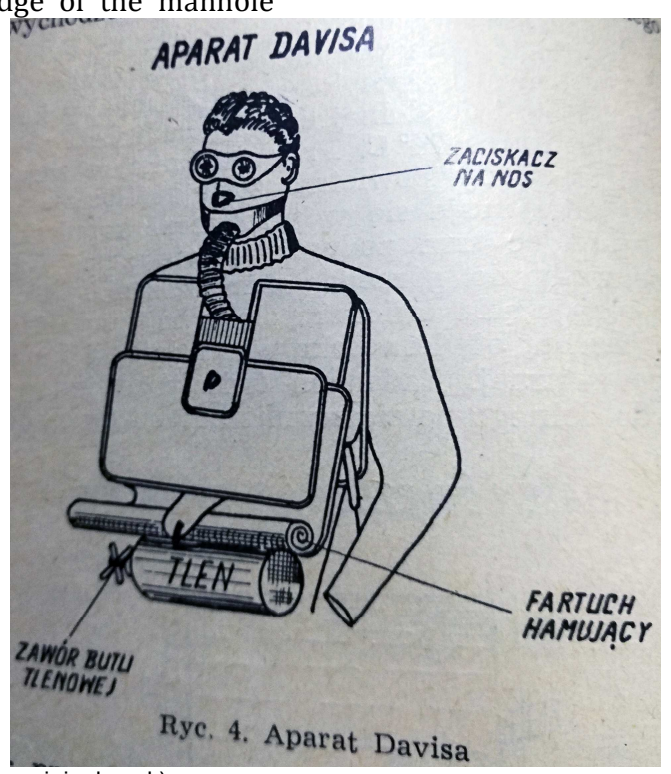

Fig. 4 Davis apparatus (a drawing scan from the original work).

When preparing the pool, the instructor used the Davis submerged escape apparatus [2] (Fig. 4.). It is a socalled open-circuit apparatus with a single cylinder of oxygen under a pressure of 150 atmospheres, which enters the breathing bag through a reduction valve, and then through a rubber hose into the airways. The main oxygen cylinder is hung at the bottom of the breathing bag. Additionally, in the lateral part of the bag there is a small spare cylinder with oxygen, which fills the bag immediately after breaking off the glass tube blocking the spare cylinder. After putting on the rescue apparatus and turning off the main valve of the oxygen cylinder, the instructor found that there was not enough oxygen. However, he disregarded this fact and descended into the swimming pool. He had no diving backup, which was an obvious violation of the regulations in force. After opening the manhole, the diver ascended to the surface, then for the second time he descended to the lower compartment of the pool, and suddenly lost consciousness. 
As stated later, the spare oxygen cylinder was ready for use. The swimming pool staff, worried that the diver did not show up, released the water from the pool and found him unconscious on the bottom. The instructor's stay under water lasted 6 minutes. Despite the immediate application of artificial respiration by mariners and rapid medical assistance, the diver could not be resuscitated. The section report indicated the following (to cite only the changes that were important for the accident):

- Heart embolism test negative.

- Food content found within the trachea and larger bronchi.

- Congestion of internal organs under the epicardium and the conjunctivae, liquid blood in the heart and vessels.

- Cause of death - suffocation (lack of oxygen).

This accident is a typical example of asphyxia due to lack of oxygen. Insufficient oxygen leads to a sudden loss of consciousness, without previous warning signs. How quickly such a loss occurs is clearly indicated by the case in which an experienced diver with developed diving instructor reflexes did not manage to activate the ready-to-use spare oxygen cylinder. In this case, if help is not immediate, the diver cannot be rescued. Accidents similar to the one described above are rare and occur when the diver does not act in accordance with the applicable regulations.
Usually, when using oxygen devices, the main emphasis is on ensuring that the diver is not subject to oxygen poisoning when breathing at a depth exceeding the permissible depth, i.e. at a pressure higher than two atmospheres, which corresponds to a depth above $20 \mathrm{~m}$ [4]. An indication of oxygen poisoning is irritation of the nervous system, which is particularly pronounced in the initial period.

\section{Conclusions}

1. The most common cause of diving accidents is failure to comply with the regulations in force.

2. In order to prevent accidents, it is important that both the on-board staff and the diver have complete knowledge regarding the proper diving technique.

3. Accidents due to damage to the diving apparatus are less common.

For the above reasons, accurate training of the diver and on-board personnel, as well as observance of the applicable regulations, careful inspection of the equipment along with the required modern communication equipment, is an indispensable condition ensuring safety at work.

\section{REFERENCES}

1. Ćwiek H.,: Underwater works, Gdańsk 1951;

2. Davis R.H.: Deep diving and Submarine Operations. London 1952;

3. Dolatkowski A.,: Treatment of Divers' Diseases. Lekarz wojskowy 1954, No. 10, p. 970;

4. Huszcza A.,: Atmospheric Pressure and its Effect on Human System. Warsaw 1951;

5. Jacobson M.J.,: Kesonnaja boleźń . Moskwa 1950;

6. Stelcner H.,: Taucher-Technik. Lubeck 1943;

7. Taillez P., Dumas F., Cousteau J.Y., Aliant J. i Devilla F.,: Polongee en Scaphandre. Paris 1949;

8. Semerau-Siemianowski M.: Internal Diseases v.I Warsaw 1951. 